\title{
Morphologically bioinspired hierarchical Nylon 6,6 electrospun assembly recreating the structure and performance of tendons and ligaments
}

\author{
Alberto Sensini ${ }^{1}$, Carlo Gotti ${ }^{1}$, Juri Belcari ${ }^{1}$, Andrea Zucchelli ${ }^{1}$, \\ Maria Letizia Focarete ${ }^{2,3}$, Chiara Gualandi ${ }^{2,4}$, Ivan Todaro ${ }^{1}$, Alexander P. Kao ${ }^{5}$, \\ Gianluca Tozzi ${ }^{5}$, Luca Cristofolini ${ }^{1,3}$
}

1 Department of Industrial Engineering, Alma Mater Studiorum-University of Bologna, I-40131 Bologna, Italy

2 Department of Chemistry 'G. Ciamician' and National Consortium of Materials Science and Technology (INSTM, Bologna RU), Alma Mater StudiorumUniversity of Bologna, I-40126 Bologna, Italy

3 Health Sciences and Technologies - Interdepartmental Center for Industrial Research (CIRI-HST), Alma Mater Studiorum-University of Bologna, I-40064 Ozzano dell'Emilia, Bologna, Italy

4 Advanced Mechanics and Materials - Interdepartmental Center for Industrial Research (CIRI-MAM), Alma Mater Studiorum-University of Bologna, I-40123 Bologna, Italy

5 Zeiss Global Centre, School of Mechanical and Design Engineering, University of Portsmouth, Portsmouth PO1 3DJ, United Kingdom

\section{Submitted to: Medical Engineering \& Physics - Special Issue on Biofabrication Version.0: $\quad 1^{\text {st }}$ February 2019 \\ Version.1: $\quad 17^{\text {th }}$ May 2019}

Statistics:

Word count (manuscript): 5023 (Introduction through acknowledgements, excluding references, captions and tables)

Word count (abstract): $\quad 248$ words

Figures: 9

Tables: 1

References: $\quad 58$

Corresponding author:

Luca Cristofolini

Department of Industrial Engineering

Alma Mater Studiorum - Università di Bologna

Via Umberto Terracini 28

40131 Bologna, Italy

e-mail: luca.cristofolini@unibo.it 


\section{$1 \quad$ Abstract}

2 Reconstructions of ruptured tendons and ligaments currently have dissatisfactory failure

3 rate. Failures are mainly due to the mechanical mismatch of commercial implants with

4 respect to the host tissue. In fact, it is crucial to replicate the morphology (hierarchical

5 in nature) and mechanical response (highly-nonlinear) of natural tendons and ligaments.

6 The aim of this study was to develop morphologically bioinspired hierarchical Nylon

76,6 electrospun assemblies recreating the structure and performance of tendons and

8 ligaments. First, we built different electrospun bundles to find the optimal orientation

9 of the nanofibers. A 2nd-level hierarchical assembly was fabricated with a dedicated

10 process that allowed tightly joining the bundles one next to the other with an electrospun

11 sheath, so as to improve the mechanical performance. Finally, a further hierarchical 3rd-

12 level assembly was constructed by grouping several 2nd-level assemblies. The

13 morphology of the different structures was assessed with scanning electron microscopy

14 and high-resolution X-ray tomography, which allowed measuring the directionality of

15 the nanofibers in the bundles and in the sheaths. The mechanical properties of the single

16 bundles and of the 2nd-level assemblies were measured with tensile tests. The single

17 bundles and the hierarchical assemblies showed morphology and directionality of the

18 nanofibers similar to the tendons and ligaments. The strength and stiffness were

19 comparable to that of tendons and ligaments. In conclusion, this work showed an

20 innovative electrospinning production process to build nanofibrous Nylon 6,6

21 hierarchical assemblies which are suitable as future implantable devices and able to

22 mimic the multiscale morphology and the biomechanical properties of tendons and

23 ligaments.

24 Keywords: Bioinspired Structures; Electrospinning; Hierarchical Devices; Tendons and 25 Ligaments 


\section{Introduction}

28 The design and development of innovative solutions to repair or substitute injured

29 tendons and ligaments is one of extreme interest in orthopaedic research. In fact,

30 approximately 30 million new cases of tendon and ligament injuries are diagnosed

31 worldwide annually [1]. From over 33 million musculoskeletal injuries per year in the

32 United States alone, almost 50\% of them are tendon and ligament related, with about

3395,000 new cases annually [2]. The difficulty in healing these tissues is mainly related

34 to their non-linear mechanical properties and complex hierarchical structure, composed

35 of collagen fibers that are axially aligned and organized in different levels of aggregation

36 [3-5]. Above all, due to low cellular activity, the injuries of elderly people generally

37 require the use of permanent inert prosthetic devices [6-8]. An inert polymeric material

38 frequently used for devices in this field is Nylon 6,6, which has been approved as an

39 implantable material [9]. For instance, Nylon 6,6 is found in commercially available

40 suture wires [10,11] and tendon grafts [12].

41 The most popular examples of inert devices for tendon and ligament are Lars ${ }^{\circledR}$ Ligament,

42 Leeds-Keio ${ }^{\circledR}$ (i.e. Poly-tape ${ }^{\circledR}$ ) and Gore-Tex ${ }^{\circledR}$ [12]. In the last two decades, several

43 studies published in literature have assessed the clinical quality of these devices [8].

44 However, even if they have adequate mechanical behavior, compared to the native

45 tendon or ligament tissue, they have a different morphology and are not hierarchically

46 structured. The Lars ${ }^{\circledR}$ Ligament is composed of aligned microfibers grouped together

47 by an external knitted membrane; Leeds-Keio ${ }^{\circledR}$ (i.e. Poly-tape ${ }^{\circledR}$ ) is a totally

$48 \mathrm{knitted} /$ waved microfibrous device; while Gore-Tex ${ }^{\circledR}$ is made of groups of aligned

49 microfibers braided together to obtain the final device. However, all these textile

50 patterns produce implantable devices have a very different morphology when compared

51 to a natural tendon or ligament [13]. In fact, tendon or ligament tissue is composed of

52 collagen nanofibers preferentially axially aligned, organized in different levels of

53 aggregation and covered by membranes of randomly arranged collagen nanofibers 
$54[3,4,14]$. The lack of bioinspired hierarchical organization of these implantable devices,

55 can often cause inflammatory outcomes and post-operative complications $[8,12]$.

56 Furthermore, several clinical follow-ups of such devices have shown controversial

57 outcomes, in terms of failure or success over a long-term period [8]. Among the others,

58 Lars $^{\circledR}$ Ligament showed the most promising results for long term positive outcomes of

59 the implants and low incidence of revision surgery in Anterior Cruciate Ligament (ACL)

60 applications [15]. However minor episodes of knee stiffness and synovitis were

61 documented in the past $[8,15,16]$. The published studies about the clinical performances

62 in ACL reconstruction using the Leeds-Keio ${ }^{\circledR}$, despite several positive results, showed

63 frequent events of re-rupture, tunnel enlargement, synovitis associated with polyester

64 particles, greater pivot-shift and laxity, especially until the early 2000s [17-20].

65 Moreover different applications of this device were explored to repair other tendons and

66 ligaments such as rotator cuff, knee extensor, Achilles tendon, iliofemoral ligament and

67 ankle lateral ligament [8]. Gore-Tex ${ }^{\circledR}$ devices showed satisfactory results to treat very

68 large rotator cuff tears and patellar reconstructions [21,22], but due to severe osteolytic

69 complications were completely abandoned for ACL applications [8,23,24].

70 A promising approach to overcome the morphological and mechanical limitations of

71 these devices is offered by the electrospinning technology. Producing polymeric

72 nanofibers by stretching solutions in high electrostatic fields, the electrospinning

73 technique has demonstrated the ability to fabricate scaffolds that mimic the tendon and

74 ligament tissue $[25,26]$. However, to date no one has used electrospinning to produce

75 complex assemblies that reproduce the hierarchical structure and mechanical properties

76 of a whole tendon or ligament [27].

77 The aim of this study was to develop morphologically bioinspired hierarchical 78 assemblies (made of inert Nylon 6,6) to replicate the biomechanical response of natural 79 tendon and ligament. For this reason, three levels of aggregation were investigated: (i) 80 bundles of random and aligned electrospun nanofibers; (ii) a 2nd-level hierarchical 
81 assembly built using the most promising type of bundles (aligned nanofibers); (iii) a 3rd-

82 level hierarchical assembly containing several 2nd-levels hierarchical assemblies. For

83 all of these structures, the morphology and the associated mechanical properties were 84 investigated.

85 
87 In order to develop a complex hierarchical structure, in the first phase two different

88 methods for producing electrospun bundles were developed: in one instance, the

89 nanofibers were randomly aligned, while in the second instance a high alignment of the

90 nanofibers was achieved. The morphology of the Bundles was characterized with

91 Scanning Electron Microscopy (SEM) and High-Resolution X-ray Computed

92 Tomography (XCT); mechanical tests were performed to assess the strength and

93 modulus of elasticity of the constructs. The most promising candidates (bundles of

94 aligned nanofibers) were used to produce the 2nd-level hierarchical assemblies, which

95 were again characterized in terms of morphology and mechanical properties. The 3rd-

96 level hierarchical assembly was built by joining three 2nd-level hierarchical assemblies,

97 and its morphology was fully characterized.

98 2.1. Materials

99 Nylon 6,6 pellets, kindly provided by DuPont (Wilmington, USA), were dissolved in a 100 trifluoroacetic acid (TFA) (Carlo Erba, Milan, Italy) and acetone (AC) (Sigma Aldrich, 101 Saint-Louis, USA) mixture, in order to obtain the following solution: $15 \%$ (w/v) solution 102 of Nylon 6,6 dissolved in TFA:AC = 50:50 (v/v).

\subsection{Identification of optimal electrospun bundle preparation}

\subsubsection{Electrospun bundles production}

105 Electrospun bundles were produced using a laboratory electrospinning machine

106 (Spinbow Lab Unit, Spinbow S.r.1., Bologna, Italy), equipped with a linear sliding 107 spinneret (carrying four syringes ejecting the same polymeric solution) and a rotating 
108 drum collector $($ diameter $=150 \mathrm{~mm}$; length $=500 \mathrm{~mm})$. A syringe pump $($ KD Scientific

109200 series, Illinois, USA) and four glass syringes were used to electrospin the solution.

110 Each syringe was connected to a stainless-steel blunt-ended needle (inner diameter $=$

$1110.84 \mathrm{~mm}$ ) with a PTFE tube. The electrospinning was performed at room temperature

112 (RT) and relative humidity $20-30 \%$. The solution was electrospun with an applied

113 voltage of $20 \mathrm{kV}$ and a feed rate of $0.50 \mathrm{~mL} \mathrm{~h}^{-1}$. The drum collector was positioned 160

$114 \mathrm{~mm}$ away from the needle tips. The sliding spinneret with the four needles had an

115 excursion of $100 \mathrm{~mm}$, with a sliding speed of $1200 \mathrm{~mm} \mathrm{~min}^{-1}$. The mats of nanofibers

116 were cut circumferentially into strips.

117 In order to reach the best configuration in terms of fiber orientation and mechanical

118 properties, different electrospun bundles were produced. Bundles made of random

119 fibers were obtained by rotating the drum collector with a low peripheral speed of 0.78

$120 \mathrm{~m} \mathrm{~s}^{-1}$ and for an electrospinning time of 1.5 hours (Fig. 1). The mats of random

121 nanofibers were cut into $70 \mathrm{~mm}$ wide strips, and manually wrapped to produce bundles,

122 with a cross-sectional diameter of approximately 550-650 micrometers. At the end of

123 the procedure, the bundles (about $470 \mathrm{~mm}$ in length) were cut in an extremity and

124 removed from the collector (Fig. 1).

125 However, in order to improve the mechanical properties of the random bundles (see

126 results section), bundles of aligned nanofibers were produced. To obtain mats of

127 nanofibers preferentially aligned in the direction of drum rotation, the drum collector

128 was rotated with a higher peripheral speed of $22.8 \mathrm{~m} \mathrm{~s}^{-1}$ during an electrospinning time

129 of 3 hours. The mats of aligned nanofibers were cut into $50 \mathrm{~mm}$ wide strips, and rolled

130 on the drum as previously described. 
133 To examine the surface morphology of the Nylon 6,6 bundles, Scanning Electron

134 Microscopy (SEM) analysis was performed. A commercial SEM (Philips 515 SEM,

135 Amsterdam, Netherlands) was used with a voltage of $15 \mathrm{kV}$, on samples sputter-coated

136 with gold. The diameter of the nanofibers and their distribution (mean and SD) were

137 measured on the SEM images of 200 fibers, by means of the image analysis software

138 ImageJ [28].

139 To measure the mean diameter of each bundle a light optical microscope (Axioskop,

140 Zeiss, Pleasanton, CA, USA) equipped with a camera (AxioCam MRc, Zeiss,

141 Pleasanton, CA, USA) was used and image analysis was performed using ImageJ [28].

142 For each bundle, the mean and standard deviation (SD) of ten measurements was

143 computed. To measure the weight of each specimen a precision balance was used (MC

144210 P, capacity resolution: $210 \mathrm{~g}$ x $0.01 \mathrm{mg}$, Sartorius, Göttingen, Germany). For each

145 bundle, the mean and SD of three measurements was computed.

146 In order to investigate the three-dimensional structure of the Nylon 6,6 bundles, high-

147 resolution x-ray tomographic scans were acquired with a laboratory XCT (Versa 510,

148 Zeiss, Pleasanton, CA, USA). For the XCT scans, the following settings were used: 40

$149 \mathrm{kV}$ Voltage, $3 \mathrm{~W}$ Power, 75.5 microAmpere tube current. Projections were collected at 150 rotational steps of $0.18^{\circ}$ over $360^{\circ}$, with a voxel size 0.4 micrometers, using 14 second 151 exposure time (scanning time of approximately 10 hours).

152 All the XCT images, were reconstructed using the Scout-and-Scan Reconstructor 153 software (Zeiss), and were visualized using XM3DViewer1.2.8 software (Zeiss). 
156 In order to quantify the distribution of orientation of the nanofibers in the bundles, the

157 Directionality plugin of ImageJ was used [28-30]. This approach allowed to quantify

158 the amount of nanofibers within a given angle from the axis. The analysis was

159 performed using a Local Gradient Orientation method following a procedure previously

160 validated [31]. For the random nanofiber bundles the Directionality analysis was

161 performed on stacks of five SEM images (magnification $=8000 \mathrm{x}$ ). For the aligned

162 nanofiber bundle a full volume investigation was performed applying the same

163 procedure to all the slices of the XCT stacks, after reslicing.

\section{2.2.4. Mechanical characterization of the bundles}

165 The mechanical properties of the random and aligned nanofiber bundles were measured

166 with a servo-hydraulic testing machine (8032, Instron, High Wycombe, UK), with a \pm 1

$167 \mathrm{kN}$ dynamic cell (Instron, High Wycombe, UK). The force signals had a noise of 0.01

$168 \mathrm{~N}$ after filtering. All the specimens were immersed in saline for two minutes before the

169 mechanical test. The test machine was operated in displacement control, adjusting the

170 actuator speed according to the actual specimen length, to obtain a strain rate of $70 \% \mathrm{~s}^{-}$

171 . This strain rate is in the range of those experienced by tendons and ligaments during

172 strenuous physiological activities [32-35].

173 Ten specimens of both random and aligned nanofiber bundles were tested. Dedicated

174 capstan grips (Fig. 5) were used to minimize the stress concentration at the specimens

175 ends. The gauge length was $47.42 \mathrm{~mm}$ (this included the free length and the portion of

176 specimen wrapped around the capstans, consistent with the BS EN 12562:1999 and the

177 ASTM D2256/D2256M-10 (2015) Standards). 
178 The mechanical characterization of the random and aligned bundles was performed to 179 identify the most biomimetic candidate, so just the typical load-strain curves and the

180 force and stress data were analyzed (see 2.3.4 section and Fig. 2).

\subsection{Optimization of the hierarchical assemblies}

182 Based on the most promising configuration from section 2.2 (see Results), aligned 183 bundles were adopted for the following steps. In order to allow easier handling and

184 stretching of the bundles in the subsequent steps of preparation of the hierarchical 185 structures, the bundles were removed from the collector without any cut, thus obtaining 186 ring-shaped bundles (Fig. 1).

\subsubsection{Fabrication of the hierarchical assemblies}

188 In order to reproduce the whole morphology of a tendon or ligament $[4,14,27]$, two

189 different electrospun bioinspired assembly were produced.

190 To group together different numbers of bundles, an innovative electrospinning 191 procedure to electrospin nanofibrous sheaths was developed (Fig. 1). These sheath were 192 designed to reproduce the morphology of the natural membranes of tendons (endotenon, 193 epitenon) or ligaments (endoligament, epiligament) [4,27]. The same electrospinning 194 parameters previously described were used.

195 Two custom made stainless-steel 6-arms capstan grips (6 cylindrical arms of $8 \mathrm{~mm}$ of 196 diameter each) were fixed in a custom-made rotating electrospinning machine. Then, 19724 bundles were hooked on the grips, 4 for each arm (Fig. 1). After this operation, a 198 Nylon 6,6 sheath of nanofibers was electrospun on the group of bundles for 12 hours. 199 The custom-made electrospinning apparatus was composed of a high-voltage power 200 supply (FuG Elektronik GmbH, Schechen, Germany), two syringe pumps (KD 
201 Scientific Legato 100, Illinois, USA), and two glass syringes containing the polymeric

202 solution, connected to stainless-steel blunt-ended needles (inner diameter $=0.84 \mathrm{~mm}$ )

203 by PTFE tubes.

204 In order to concentrate the nanofibers on the group of bundles, a flat aluminum collector 205 plate (200 $\mathrm{mm}$ high and $50 \mathrm{~mm}$ wide) was placed behind the bundles (Fig. 1). To pre206 strain the nanofibers of the sheath on the final assembly surface, the group of bundles 207 was in a static position, and intermittently put in rotation (approximately $20 \mathrm{rpm}$ for 1

208 minute every 5 minutes), while the sheath was being electrospun (Fig. 1).

209 Finally, in order to produce a hierarchical assembly to completely simulate the structure

210 of a whole tendon or ligament [4,27], including the endotenon/endoligament sheaths and

211 the tertiary fiber bundles inside, a 3rd-level hierarchical assembly was produced. First,

212 three Nylon 6,6 2nd-level hierarchical assemblies, with five ring-shaped bundles each,

213 were produced as previously described (with an electrospinning session of 10 hours

214 each). Then, the extremities of the three 2nd-level hierarchical assemblies were tied

215 together with paper tape, and fixed in the machine (Fig.1). To produce the

216 epitenon/epiligament-like sheath, the same procedure and methods previously described

217 were used, with and electrospinning session of 10 hours (Fig. 1).

218 2.3.2. Morphological investigation of the hierarchical assemblies

219 The SEM and light optical microscope investigations on the 2nd-level and 3rd-level

220 hierarchical assemblies were performed with the same parameters previously described

221 in section 2.2.2.

222 To investigate the three-dimensional structure of the Nylon 6,6 hierarchical assemblies,

223 the XCT scans were acquired with a different high-resolution x-ray tomography system

224 (Versa 520, Zeiss, Pleasanton, CA, USA). The following parameters were used 
225 (depending on the shape and thickness of the specimens): (i) 2nd-level hierarchical 226 assembly: $50 \mathrm{kV}$ Voltage, $4 \mathrm{~W}$ Power, 80 microAmpere tube current, 5.27 micrometers

227 voxel size, 1.75 second exposure time, rotational steps of $0.12^{\circ}$ over $360^{\circ}$, for a scanning 228 time of 7.5 hours; (ii) 3rd-level hierarchical assembly: $50 \mathrm{kV}$ Voltage, $3 \mathrm{~W}$ Power, 60 229 microAmpere tube current, 5.27 micrometers voxel size, 1.75 second exposure time, 230 rotational steps of $0.12^{\circ}$ over $360^{\circ}$, for a scanning time of 7.5 hours.

231 All the XCT images, were reconstructed using the Scout-and-Scan Reconstructor 232 software (Zeiss), and were visualized using XM3DViewer1.2.8 software (Zeiss).

\section{2.3.3. Directionality of the nanofibers of the sheath and of the internal bundles}

234 In order to quantify the orientation of the nanofibers in the electrospun sheaths and in 235 the bundles inside the assemblies, the Directionality plugin of ImageJ was used [28-30], 236 as described above in the bundles section. The Directionality analysis was performed 237 with two different approaches derived from Sensini et al. [31].

238 For the external sheaths, the Directionality analysis was performed on stacks of 5 SEM 239 surface images (magnification $=8000 \mathrm{x}$ ). To assess the orientation of the bundles inside 240 the hierarchical assemblies, a full volume investigation was performed applying the 241 procedure to all the slices of the XCT stacks, after a reslice.

\section{2.3.4. Mechanical characterization of the hierarchical assemblies}

243 The mechanical characterization was performed both on the ring-shaped bundles and on

244 the 2nd-level hierarchical assemblies (due to limited availability of specimens, the 245 mechanical tests were not performed on the 3rd-level hierarchical assembly).

246 As the hierarchical assemblies were built with ring-shaped bundles (as opposed to the 247 straight bundles tested before, see 2.2.4) the mechanical test was performed starting from 
248 the single ring-shaped bundles. Ten specimens of ring-shaped bundles were tested using

249 capstan grips with the same strain rate as before (Fig. 9). The gauge length was $220 \mathrm{~mm}$

250 (consistent to the ASTM D1414 Standard).

251 Finally, three specimens of 2 nd-level hierarchical assembly were tested. The cross-

252 sectional diameter of each specimen was measured as above (mean and SD between 30

253 measurements in three different sections). The specimens were weighed with the same

254 precision balance. In order to minimize the stress concentration, the specimens were

255 tested directly on the stainless-steel 6-arms capstan grips, mounted on the Instron testing

256 machine (Fig. 9).

257 The following indicators were considered: Yield Stress $\left(\sigma_{Y}\right)$, Yield Strain $\left(\varepsilon_{Y}\right)$, Modulus

258 of Elasticity $(\mathrm{E})$, Failure Force $\left(\mathrm{F}_{\mathrm{F}}\right)$, Failure Stress $\left(\sigma_{\mathrm{F}}\right)$, Failure Strain $\left(\varepsilon_{\mathrm{F}}\right)$, Unit Work

259 to Yield $\left(\mathrm{L}_{\mathrm{Y}}\right)$, Unit Work to Failure $\left(\mathrm{L}_{\mathrm{F}}\right)$ (Fig. 2). The force-displacement curves were

260 converted to stress-strain curves using two different approaches:

261 - To describe the macroscopic mechanical behavior of the specimen, the apparent

262 stress was computed dividing the force by the cross-sectional area measured 263 before the test.

264 - To quantify the net mechanical properties, the net stress was also computed

265 dividing the apparent stresses by the volume fraction $(v)$ of the specimens.

266 - The apparent and the net modulus of elasticity (E), and unit works to failure

$267 \quad$ were computed $\left(\mathrm{L}_{\mathrm{Y}}, \mathrm{L}_{\mathrm{F}}\right)$

268 The volume fraction $(v)$ was calculated by using the equation:

$$
v=w /(\mathrm{L} \cdot A \cdot \rho)
$$

270 Where:

$271 \quad w \quad$ is the weight of the specimen

$272 \quad L \quad$ is length of the specimen, 
$273 A$ is the cross-sectional area of the specimen

$274 \rho \quad$ is the density of the raw material (Nylon $6,6=1.14 \mathrm{~g} / \mathrm{cm}^{3}$ )

\section{3. Results}

\section{3.1. Comparison between random and aligned bundles}

277 The electrospun bundles of random and aligned Nylon 6,6 nanofibers were compared.

278 The random bundles had a cross-sectional diameter of $0.52 \pm 0.05 \mathrm{~mm}$, and the aligned

279 bundles of $0.52 \pm 0.06 \mathrm{~mm}$. The volume fraction $(v)$ for the random bundles was $280 \quad 0.21 \pm 0.03$ and $0.30 \pm 0.04$ for the aligned bundles.

281 3.1.2. Morphological investigation of the bundles

282 The SEM investigation showed that the nanofibers of both the random bundles and the

283 aligned bundles were homogeneous, smooth, continuous, and with no defects such as

284 beads (Fig. 3). The nanofibers had consistent mean cross-sectional diameter of $0.23 \pm$ 2850.02 micrometers. The different orientation of the nanofibers in the random and in the 286 aligned bundles was clearly visible.

287 The XCT investigation of the random bundles showed that nanofibers were randomly 288 arranged both on the surface and inside the bundle (Fig. 3). Few wrapping defects were 289 noted in the internal body of random bundles (Fig. 3).

\section{3.1.3. Directionality of the nanofibers}

291 The Directionality analysis confirmed the different preferential orientation of the 292 nanofibers in the aligned bundles as opposed to the random ones (Fig. 4). The random 293 bundles showed a dispersion of the orientation of the nanofibers so that about $7 \%$ of 294 nanofibers fell in each bin. The aligned bundles had a predominant peak in the range of 
$2950^{\circ}-6^{\circ}$ from the bundle axis $(42.7 \% \pm 3.1 \%$ of the total $)$, and a Gaussian-like distribution.

296 A small amount of nanofibers of $0.78 \% \pm 0.15 \%$ was perpendicular to the bundle $\left(84^{\circ}\right.$ $\left.29790^{\circ}\right)$

\section{3.1.4. Mechanical properties of the bundles}

299 The load-strain curves revealed a more deformable behavior for the random bundles and

300 a stiffer behavior for the aligned bundles (Fig. 5). Both types of bundles showed a 301 nonlinear toe region up to $1-4 \%$ strain (Fig. 5). The random bundles had a failure force 302 of $F_{F}=3.27 \pm 0.61 \mathrm{~N}$, and were weaker than the aligned ones $\left(F_{F}=14.3 \pm 2.7 \mathrm{~N}\right)$.

303 After the toe region, the random bundles showed a short elastic region up to an apparent

304 yield stress of $\sigma_{Y}=3.27 \pm 0.90 \mathrm{MPa}$ and a final ductile region up to an apparent failure

305 stress of $\sigma_{\mathrm{F}}=15.6 \pm 2.8 \mathrm{MPa}$ (Fig. 5). The aligned bundles also showed higher apparent

306 failure stress $\left(\sigma_{\mathrm{F}}=68.7 \pm 15.0 \mathrm{MPa}\right)$ compared to the random bundles (Fig. 5). For both

307 of the bundle types, the net mechanical properties were 3-5 times higher than the 308 apparent ones (Table 1).

3093.2 Properties of the hierarchical assemblies

310 The ring-shaped bundles and the hierarchical assemblies made of such bundles were

311 compared. The bundles used for the assemblies were homogeneous, and had a cross-

312 sectional diameter of $0.47 \pm 0.04 \mathrm{~mm}$. Three 2 nd-level hierarchical assemblies were 313 prepared, each with 24 ring-shaped bundles. The 2 nd-level assemblies had a final cross314 sectional diameter of $4.3 \pm 0.57 \mathrm{~mm}$, and a length of $220 \mathrm{~mm}$ (Fig. 6). The bundles 315 inside the assemblies were tightly grouped together and covered with a homogeneous 316 nanofibrous sheath (Fig. 6). The volume fraction $(v)$ for the single bundles was $v=0.33$ 
$317 \pm 0.02$. The 2 nd-level hierarchical assemblies had a lower volume fraction $v=0.22 \pm$

3180.05 , due to the free-volume between the single bundles.

319 The 3rd-level hierarchical assembly had a cross-sectional diameter of $4.6 \pm 0.17 \mathrm{~mm}$

320 with a length of $220 \mathrm{~mm}$. Observing the 3rd-level hierarchical assembly, the original

321 2nd-level hierarchical assemblies were still distinguishable; they were tightly compacted

322 inside the external nanofibrous sheath (Fig. 6). The volume fraction of the 3rd-level

323 hierarchical assembly was $v=0.175$.

\section{3.2.1 Morphology of the hierarchical assemblies}

325 The SEM investigation showed that the nanofibers in the hierarchical assemblies were

326 homogeneous, smooth, continuous, and with no defects such as beads (Fig. 7). The

327 nanofibers of the electrospun sheaths had consistent mean cross-sectional diameter of

$3280.23 \pm 0.03$ micrometers. The bundles were tightly grouped inside the nanofibrous 329 sheaths (Fig. 7).

330 The XCT investigation on the 2nd-level hierarchical assemblies revealed that the sheath 331 was homogeneous across the surface of the hierarchical assembly, with the presence of

332 some circular defects. In the internal volume of the 2 nd-level hierarchical assemblies, 333 the bundles were axially aligned (Fig. 7). The XCT reconstructions of the 3rd-level 334 hierarchical assembly showed that: (i) the nanofibrous sheaths were homogeneous, both 335 the external and the internal with the presence of a few circular defects (Fig. 7) and (ii) 336 the 2nd-level hierarchical assemblies forming the 3rd-level assembly were axially 337 aligned, as well as the single bundles they were made of (Fig. 7). 
339 The Directionality investigation showed that the nanofibers of the sheaths for the

340 hierarchical assemblies had a slight preferential circumferential orientation (Fig. 8):

341 more than $45 \%$ of the nanofibers fell in the range of $66^{\circ}-90^{\circ}$ for the 2 nd-level

342 hierarchical assembly; more than $48 \%$ of the nanofibers fell in the range of $66^{\circ}-90^{\circ}$ for

343 the 3rd-level assembly.

344 The preferential axial of alignment of the bundles and the nanofibers inside the bundles

345 was confirmed by the XCT-based Directionality investigation (Fig. 8). All the

346 specimens had a predominant peak in the range of $0^{\circ}-6^{\circ}$ and a Gaussian-like dispersion.

347 The 2nd-level hierarchical assembly showed strong axial alignment, with $52.0 \% \pm 5.1 \%$

348 in the range $0^{\circ}-6^{\circ}$. Similarly, the 3rd-level hierarchical assembly had a strong axial

349 alignment $\left(47.3 \% \pm 5.7 \%\right.$ of the nanofibers were peak in the range of $0^{\circ}-6^{\circ}$ from the 350 axis).

351 3.2.3. Comparison of the mechanical properties of the single bundles and of the 352 hierarchical assembly

353 The typical load-strain curves of the single ring-shaped bundles and 2nd-level 354 hierarchical assembly confirmed a brittle behavior with a nonlinear toe region up to 1 $3554 \%$ of strain (Fig. 9). The single ring-shaped bundles showed a failure force of $F_{F}=$ $35621.8 \pm 1.7 \mathrm{~N}$ (mean and SD of ten specimens) and the 2nd-level hierarchical assemblies 357 of $F_{F}=330 \pm 11.0 \mathrm{~N}$ (mean and SD of three specimens) (Fig. 9).

358 The bundles had values of apparent failure stress $\sigma_{\mathrm{F}}=63.4 \pm 10.9 \mathrm{MPa}\left(\varepsilon_{\mathrm{F}}=9.29 \pm\right.$ $3591.02 \%)$ and the hierarchical assemblies of $\sigma_{\mathrm{F}}=22.9 \pm 5.0 \mathrm{MPa}\left(\varepsilon_{\mathrm{F}}=8.58 \pm 0.20 \%\right)$ 
360 respectively (Fig 9). The modulus of elasticity of the single bundles was $\mathrm{E}=877 \pm 83.1$

$361 \mathrm{MPa}$ and for the hierarchical assembly $\mathrm{E}=343 \pm 87.0 \mathrm{MPa}$ (Fig. 9).

362 The unit work to failure for the bundles was $\mathrm{L}_{\mathrm{F}}=0.25 \pm 0.08 \mathrm{~J} / \mathrm{mm}^{3}$ and $\mathrm{L}_{\mathrm{F}}=0.08 \pm$

$3630.02 \mathrm{~J} / \mathrm{mm}^{3}$ for the 2nd-level hierarchical assemblies (Fig. 9).

364 The net mechanical properties (computed considering the volume fraction $v$ ) were 4-6

365 times higher than apparent ones (Table. 1).

\section{4. Discussion}

367 The aim of the present study was to develop an innovative morphologically bioinspired

368 electrospun nanofibrous assembly, by using non-resorbable Nylon 6,6, to replicate the

369 hierarchical structure and the mechanical properties of a whole tendon or ligament.

370 Nylon 6,6 was selected for its wide range of clinical applications, such as for suture

371 wires and implantable non-resorbable devices [9].

372 In order to replicate every single hierarchical level of aggregation of the collagen fibrils

373 inside the tendon and ligament tissue [3,4,14] (Fig. 6), different electrospun bundles

374 were produced.

375 Firstly, random and aligned nanofiber bundles were obtained by means electrospinning

376 Nylon 6,6 on a drum collector, rotating at different speed. In both cases, the nanofibers

377 had the same diameter of the collagen fibrils [3,4,14] observed within tendons and

378 ligaments. The random bundles were not satisfactory, because they had a morphology

379 and an arrangement of the nanofibers, assessed with SEM and XCT imaging (Fig. 3),

380 far from the tendon and ligament fascicles [36]. Furthermore, their mechanical

381 properties were lower than the human tendon and ligament fascicle [14,37] (Fig. 5). For

382 all these reasons the random bundles were discarded as candidates. The aligned bundles

383 were selected as best fascicle-inspired candidates. Firstly, the SEM and the XCT images 
384 (Fig. 3) confirmed that the morphology was similar to the collagen fascicles $385[3,14,36,38]$. The Directionality analysis on the XCT scan of the aligned bundle (Fig.

386 4) confirmed that the alignment of the Nylon 6,6 nanofibers was similar to that of the 387 tendon and ligament collagen fibrils [39]. Finally, the apparent modulus of elasticity of 388 our Nylon 6,6 aligned bundles $(878 \pm 83 \mathrm{MPa})$ was in the same range of the human 389 tendon and ligament fascicles (between 63.5 and $317 \mathrm{MPa}[14,37])$. The apparent failure 390 stress of the Nylon 6,6 aligned bundles $(63.5 \pm 11.0 \mathrm{MPa})$ was superior to the human 391 tendon and ligament fascicles (between 6.8 and 28.1 MPa [14,37]) (Fig. 5). These 392 findings are consistent with previous studies on electrospun bundles [25,27,40,41].

393 Subsequently, in order to reproduce the whole structure of a tendon or ligament $[3,4,14]$, 394 several ring-shaped bundles were grouped together, obtaining the 2nd-level hierarchical 395 assembly (Fig. 6). To do this, a dedicated procedure to electrospin sheath was developed 396 (Fig. 1) in order to mimic the morphology of the epitenon/epiligament membranes of 397 tendons and ligaments $[3,4,14]$. The Directionality analysis on XCT scans confirmed a 398 pronounced axial alignment of the nanofibers inside the 2nd-level assembly, and a slight 399 circumferential alignment of the nanofibers in the outer sheath. Compared to previous 400 similar processes [42-46], our method allowed a finer tuning of the level of compaction 401 of the bundles. In fact, the degree of circumferential orientation can be controlled 402 through the electrospinning procedure by matching the process parameters (i.e. 403 static/rotational time and the rotational speed of the device) during the production of the 404 sheaths (Fig. 8). Thus, it was also possible to adjust the final cross-section of the 405 assemblies themselves, improving their overall mechanical properties (Fig. 9).

406 As this procedure was particularly flexible, we were able to produce 3rd-level 407 hierarchical assemblies by grouping a number of 2nd-level hierarchical assemblies (Fig. 408 6). The 3rd-level assemblies incorporate sheaths that mimicked the tendon and ligament 
409 endotenon/endoligament membranes $[3,4,14]$. The Directionality analysis confirmed a

410 pronounced axial alignment of the nanofibers inside the 3rd-level assembly. The slightly

411 lower values of alignment for the 3rd-level assembly compared to the 2nd-level

412 assemblies were caused by the higher percentage of nanofibers in the different sheaths

413 forming the 3rd-level assembly. These hierarchical assemblies showed and

414 unprecedented morphology, biomimicking every single collagen structure that compose

415 a whole natural tendon or ligament $[3,4,14]$.

416 Both the ring-shaped bundles and the 2nd-level hierarchical assemblies showed a 417 nonlinear toe region up to $1-4 \%$ strain, similar to the behavior of the natural fascicles, 418 tendons and ligaments (i.e. $1.5-4 \%$ ) [5,14,37]. After the toe region, both the bundles 419 and the 2nd-level hierarchical assemblies exhibited a linear elastic behavior, up to $9 \%$ 420 strain, before failing (again, similar to the behavior of the natural tendons and ligaments)

421 (Fig. 9). The single bundles had a modulus of elasticity higher than the fascicles of 422 tendons and ligaments $[5,14,37]$. The hierarchical assembly had a similar modulus of 423 elasticity to natural tendons and ligaments (range: 20-3000 MPa [5,14]). The maximum 424 strain of the bundles was in the same range of collagen fascicles and of natural tendons 425 and ligaments (range: 9-25\% [5,37,47]). The failure strain of the hierarchical 426 assemblies was in the range of the natural tendons and ligaments (range: 8-120 MPa $427[5,14])$. The apparent failure stress of the bundles was $\sigma_{\mathrm{F}}=63.4 \pm 10.9 \mathrm{MPa}$. These 428 values were higher than the fascicles of natural tendons and ligaments (range: 6-40 MPa $429[5,37,47])$. The apparent failure stress for the hierarchical assemblies was $\sigma_{\mathrm{F}}=22.9 \pm$ $4305.0 \mathrm{MPa}$, which is in the same range observed in natural tendons and ligaments (range: 431 1-116 MPa [5,14]). As expected, the modulus of elasticity and the failure stress of the 432 2nd-level hierarchical assembly was lower than that of the single bundles. This may be 433 due to the fact that the apparent stress in the hierarchical assembly is calculated over the 
434 total cross-sectional area (which includes the actual cross-section of the bundles, but

435 also some unavoidable empty space). Similarly, the values of net stress (i.e. computed

436 considering the volume fraction actually filled by nanofibers) were significantly higher

437 (4-6 times) than the apparent ones.

438 Altogether, these properties can grant excellent mechanical performance, and a

439 biomimetic behavior of the hierarchical assembly. Considering that the Nylon 6,6 is an

440 inert material, the possible applications in reconstructive surgery could include

441 replacement of injured tendons or ligaments for the elderly patients (i.e. age greater than

44260 years). In fact, due to the low metabolic activity in the elderly, regenerative medicine

443 (i.e. resorbable scaffolds) is not recommended.

444 Most of the previous electrospun scaffolds reported for tendon and ligament 445 replacements consist of braided, twisted or knitted fibers [46,48-52] which do not 446 replicate the morphology of natural tissues. Compared to previous literature results, the 447 method herein proposed to produce electrospun sheaths confers a better compaction of 448 the single bundles in the multiscale hierarchical scaffold [46,48-52]; thus, providing 449 optimal compromise between morphology and mechanical properties.

450 Moreover, such high biofidelic hierarchical assemblies will also be suitable as artificial 451 tendons or ligaments for in vitro biomechanical validations tests or surgical training. In 452 fact, to the best of our knowledge, there are no specific devices available on the market 453 for such applications. The previous attempts in this field were absolutely trivial and not 454 biomimetic [53-55].

455 A limitation of this study should be mentioned: some droplets were created during 456 deposition of the electrospun sheaths (Fig. 7). Such defects might have reduced the 457 ability of the sheath to tightly bind the bundles together which might have reduced the 458 improvement in mechanical properties deriving from the compaction of the bundles. In 
459 the future, these defects could be avoided by optimizing the flow rate of the Nylon 6,6

460 solution, possibly further improving the mechanical strength of the assemblies.

461 The XCT investigation was extremely challenging because of the small diameter of the

462 electrospun nanofibers, and of the low attenuation of the polymer $[31,41,51,52,56,57]$.

463 Videos of the XCT scans of a single bundle of aligned nanofibers and of 2nd-level 464 hierarchical assembly are available in the Supplementary Materials through 465 ScienceDirect. Additional images and videos of the XCT scans are available through 466 Figshare (single aligned bundle: https://doi.org/10.6084/m9.figshare.7636580.v4; 2nd467 level hierarchical assembly: https://doi.org/10.6084/m9.figshare.7636592.v3; 3rd-level 468 hierarchical assembly: https://doi.org/10.6084/m9.figshare.7636595.v3 ).

469 In conclusion this work showed an innovative electrospinning production process to 470 design and build nanofibrous Nylon 6,6 hierarchical assemblies, suitable as future 471 implantable devices, able to mimic the multiscale morphology and the biomechanical 472 properties of tendons and ligaments. 


\section{Acknowledgments}

475 The Italian Ministry of University and Research (MIUR) is acknowledged. The mobility 476 of Alberto Sensini was funded by the University of Bologna (Marco Polo grant). The

477 Zeiss Global Centre at the University of Portsmouth is greatly acknowledged for the 478 support in X-ray imaging and data post-processing. The authors gratefully acknowledge 479 the Giuseppe Valli for the valuable suggestions and for 3D-printing the 6-arms capstan 480 grips.

482 Competing interest: None declared.

484 Funding: Funding from the Italian Ministry of University and Research (MIUR) is 485 acknowledged. The mobility of Alberto Sensini was funded by the University of 486 Bologna (Marco Polo grant).

488 Ethical approval: Not required. 

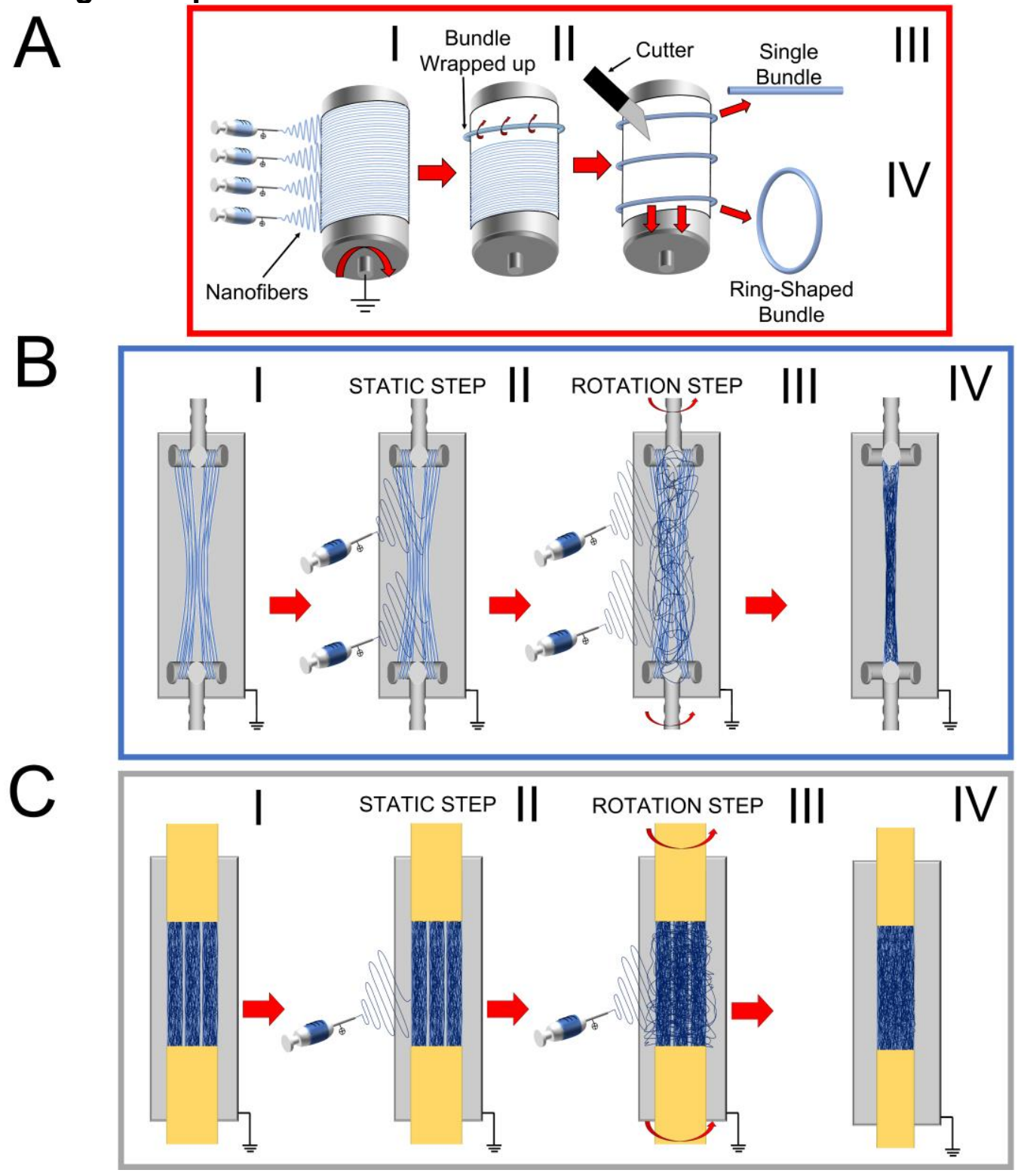

492 Fig. 1 - Electrospinning setups and procedures to produce the bundles and the

493 hierarchical devices. A) Bundles production: I) random or aligned nanofibers were

494 electrospun on the rotating drum collector; II) mats of nanofibers cut in strips and

495 manually wrapped to obtain the bundles; III) Some bundles were cut for remove them

496 from the drum (single bundles); IV) other bundles were removed from the drum without

497 cutting (ring-shaped bundles). B) 2nd-level hierarchical assembly production: I) ring-

498 shaped bundles of aligned nanofiber were hooked on the 6-arms capstan grip; II)

499 electrospun sheath production during the static step; III) during the rotation step the mat 
500 of nanofibers was torn from one side of the collector and wrapped around the group of

501 bundles; IV) final 2nd-level hierarchical assembly ready to be tested. B) 3rd-level

502 hierarchical assembly production: I) three 2nd-level hierarchical assembly grouped

503 together; II) electrospun sheath production during the static step; III) during the rotation

504 step the mat of nanofibers was torn from one side of the collector and wrapped around

505 the group of 2nd-level hierarchical assembly; IV) final 3rd-level hierarchical assembly 506 ready to be characterized.

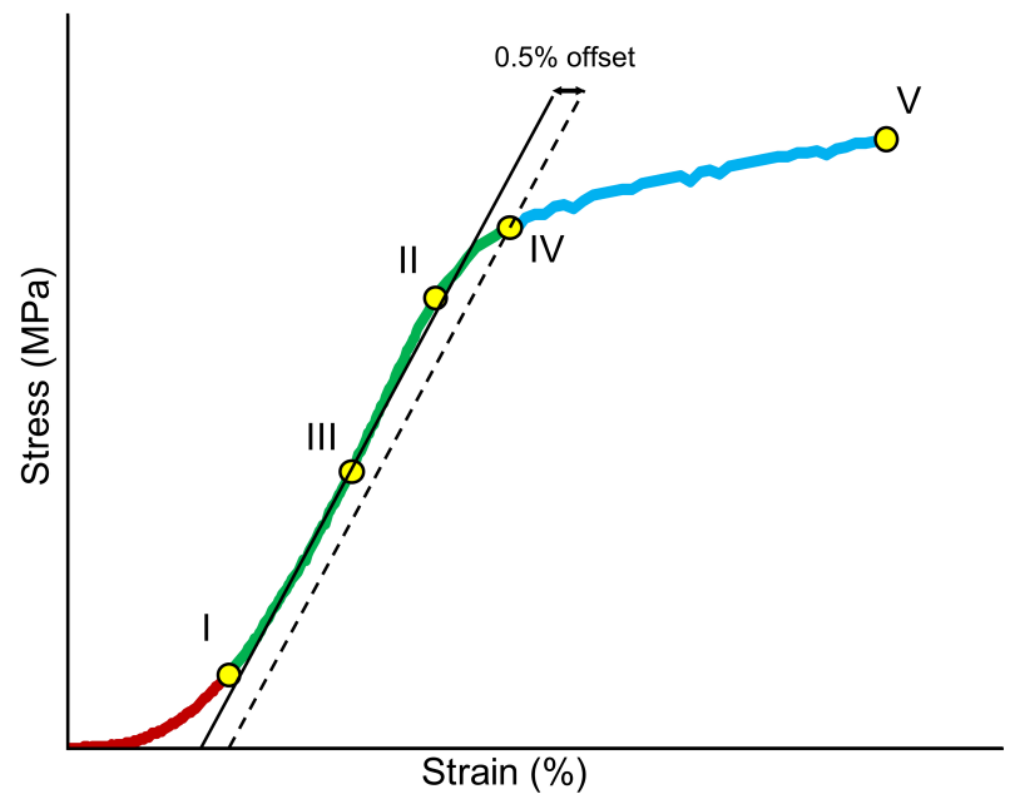

508 Fig. 2 - Post processing of the stress-strain curves. The stress-strain curves were 509 qualitatively similar for the single bundles and for the hierarchical assemblies, but the 510 magnitude of the stress and strain achieved were different. The failure stress $\left(\sigma_{\mathrm{F}}\right)(\mathrm{V})$ 511 was identified as the highest stress in the entire curve. The starting point of the linear 512 region (I) was identified as $20 \%$ of the failure stress $\left(\sigma_{\mathrm{F}}\right)$ for the bundles of aligned 513 nanofibers and the 2nd-level hierarchical assembly, and as $5 \%$ of the failure stress $\left(\sigma_{\mathrm{F}}\right)$

514 for the bundles of random nanofibers (the different threshold was required due to the 515 different behaviour of the two types of bundle). The initial toe region (from $0 \mathrm{~N}$ to I) 
516 was disregarded. An initial guess for the yield strain was visually identified (II). A first

517 linear regression (solid line) was applied to the first $50 \%$ of the linear region, between

518 points (I) and (III) (III was half-way between I and II). A second line parallel to the first

519 regression was drawn with an offset of $0.5 \%$ strain (dashed line). The limit of

520 proportionality was defined with the $0.5 \%$-strain offset criterion as the intersection (IV)

521 between the latter line and the stress-strain curve. The modulus of elasticity (E) was

522 calculated as the slope of a new regression line between (I) and (IV). The unit work to

523 yield $\left(\mathrm{L}_{\mathrm{Y}}\right)$ and to failure $\left(\mathrm{L}_{\mathrm{F}}\right)$ were calculated as the integrals under the curves (with the

524 method of trapezoids). Two plots were obtained for each specimen: one reporting the

525 apparent stress, the other one with the net stress. 


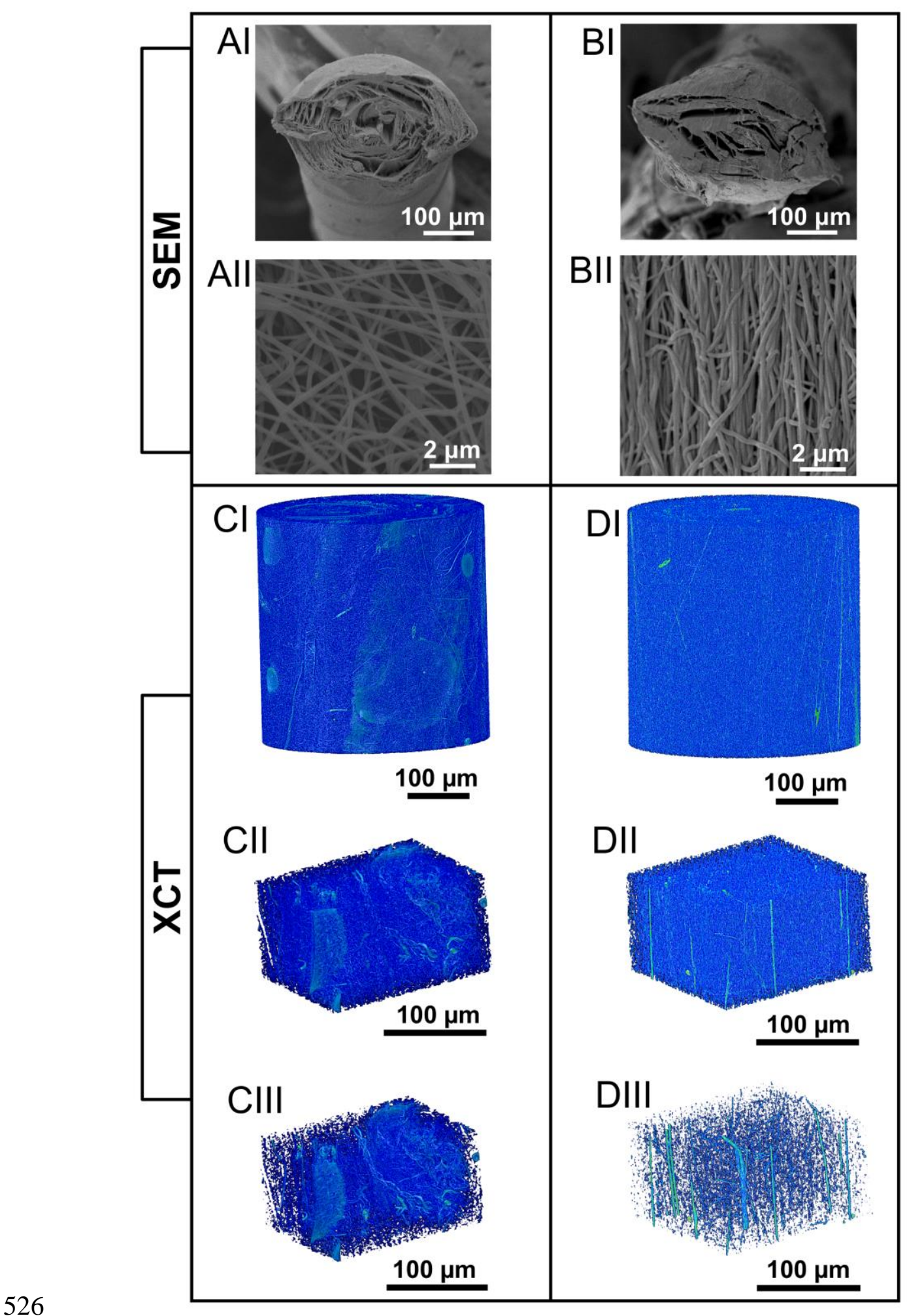

527 Fig. 3 - Imaging of the random and of the aligned bundles. A) SEM images of a random

528 nanofiber bundle. B) SEM images of an aligned nanofiber bundle. The sections of the

529 bundles (magnification $=100 x$ ) are visible in part $\mathrm{I}$; the surface of the bundle

530 (magnification $=8000 \mathrm{x}$ ) are visible in part II. C) XCT images of a random nanofiber 
531 bundle; D) XCT images of an aligned nanofiber bundle (0.4 micrometers of voxel size).

532 The sections of the bundles are visible in part I; an internal crop showing the alignment

533 of the nanofibers inside the bundle is reported in part II; tuning the thresholding the most

534 internal nanofibers become visible in part III.

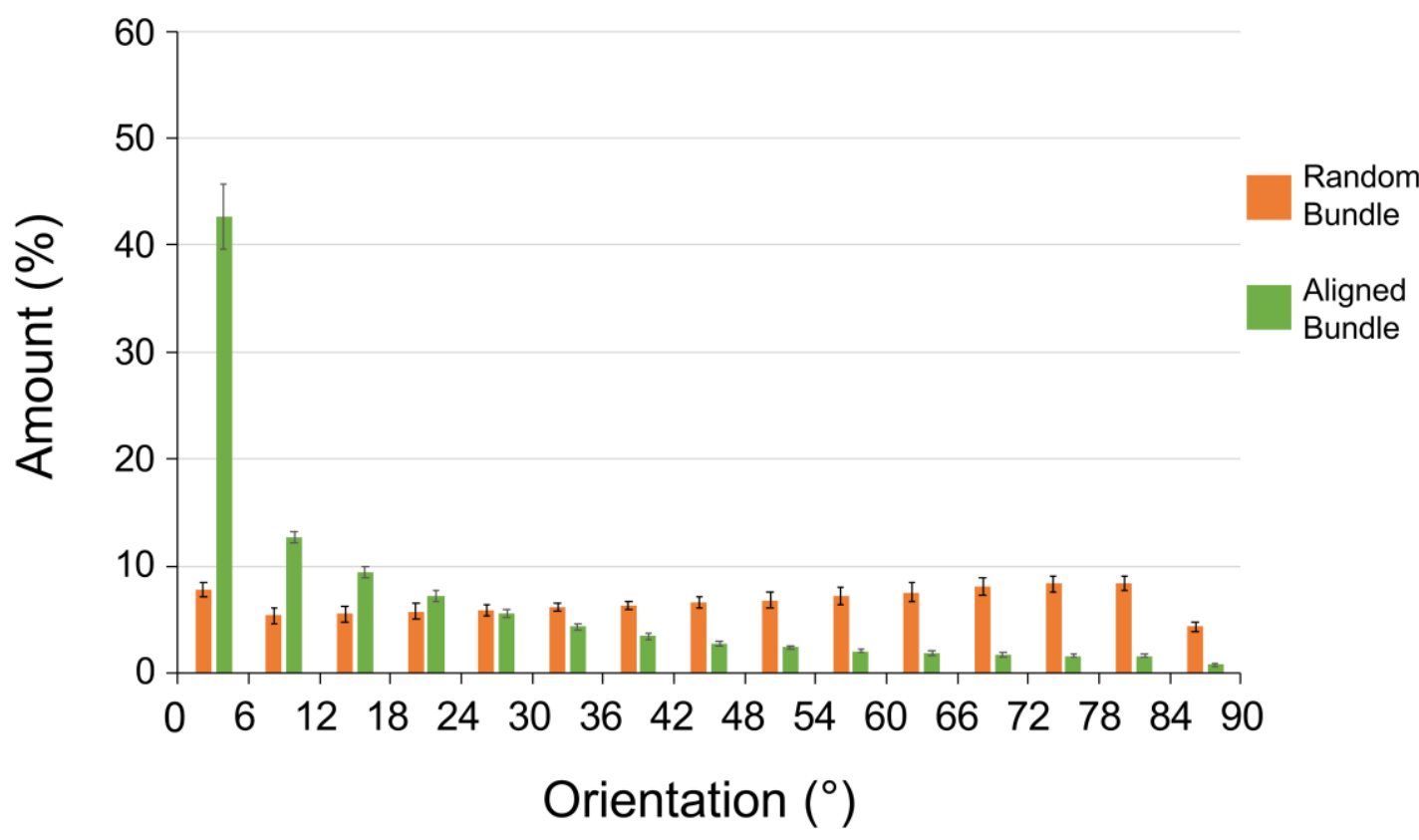

536 Fig. 4 - Directionality of the nanofibers in the random and in the aligned bundles. The 537 directionality histograms show the distribution of the nanofibers in the different 538 directions for the two types of bundles. An angle of $0^{\circ}$ means that the nanofibers were 539 aligned with the axis of the bundle, an angle of $90^{\circ}$ means that the nanofibers were 540 perpendicular to the bundle. 

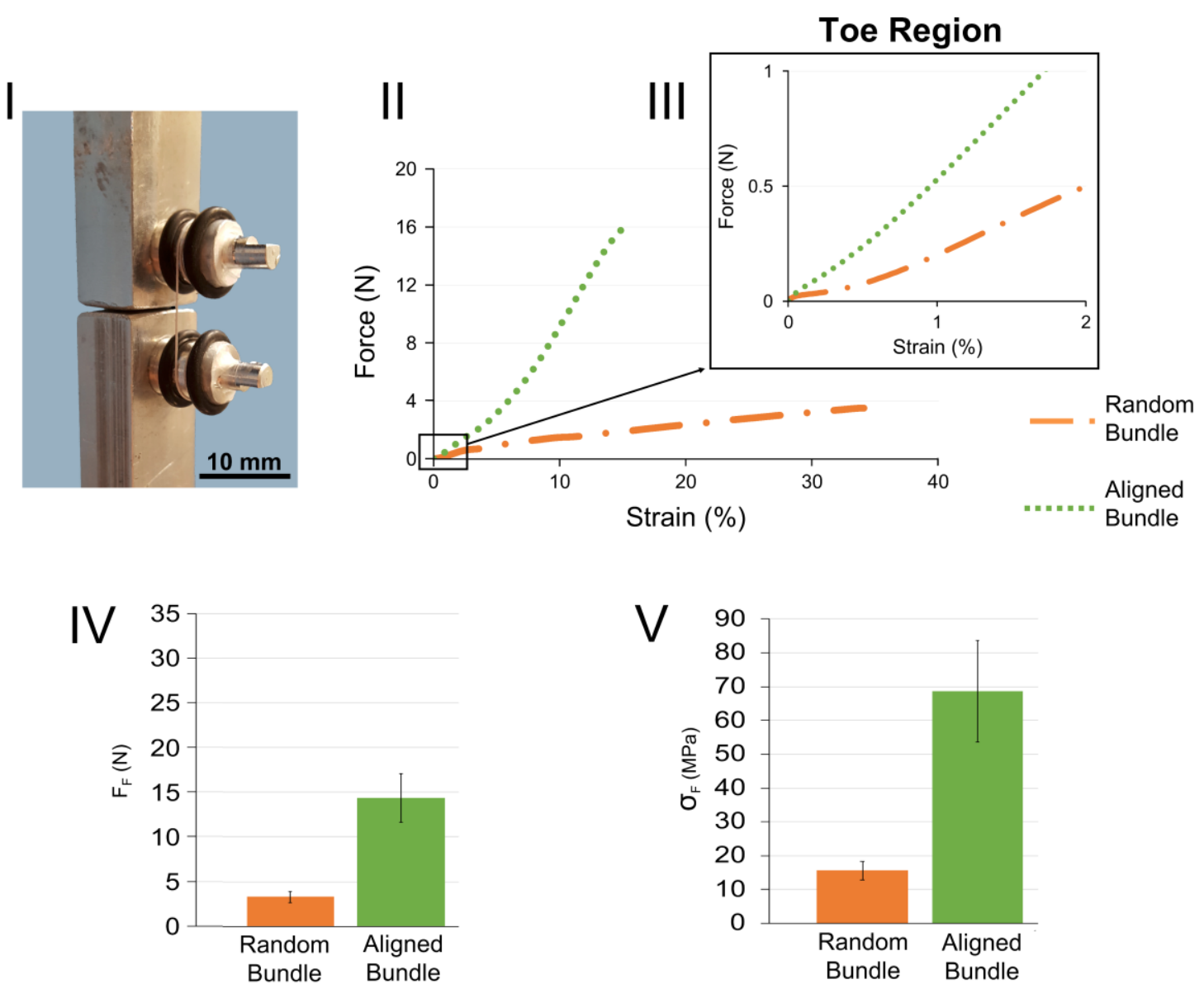

542 Fig. 5 - Mechanical characterization of the bundles of random nanofiber bundles and of

543 aligned nanofibers. I) Tensile test setup with custom-made capstan grips. II) typical

544 load-strain curves of the random bundles and the aligned bundles; III) zoom-in of the

545 nonlinear toe region. Comparison between the mechanical properties of the random and

546 of the aligned bundles: IV) failure force $\left.\left(\mathrm{F}_{\mathrm{F}}\right) ; \mathrm{V}\right)$ apparent failure stress $\left(\sigma_{\mathrm{F}}\right)$. The

547 corresponding net mechanical properties are reported in Table 1. 


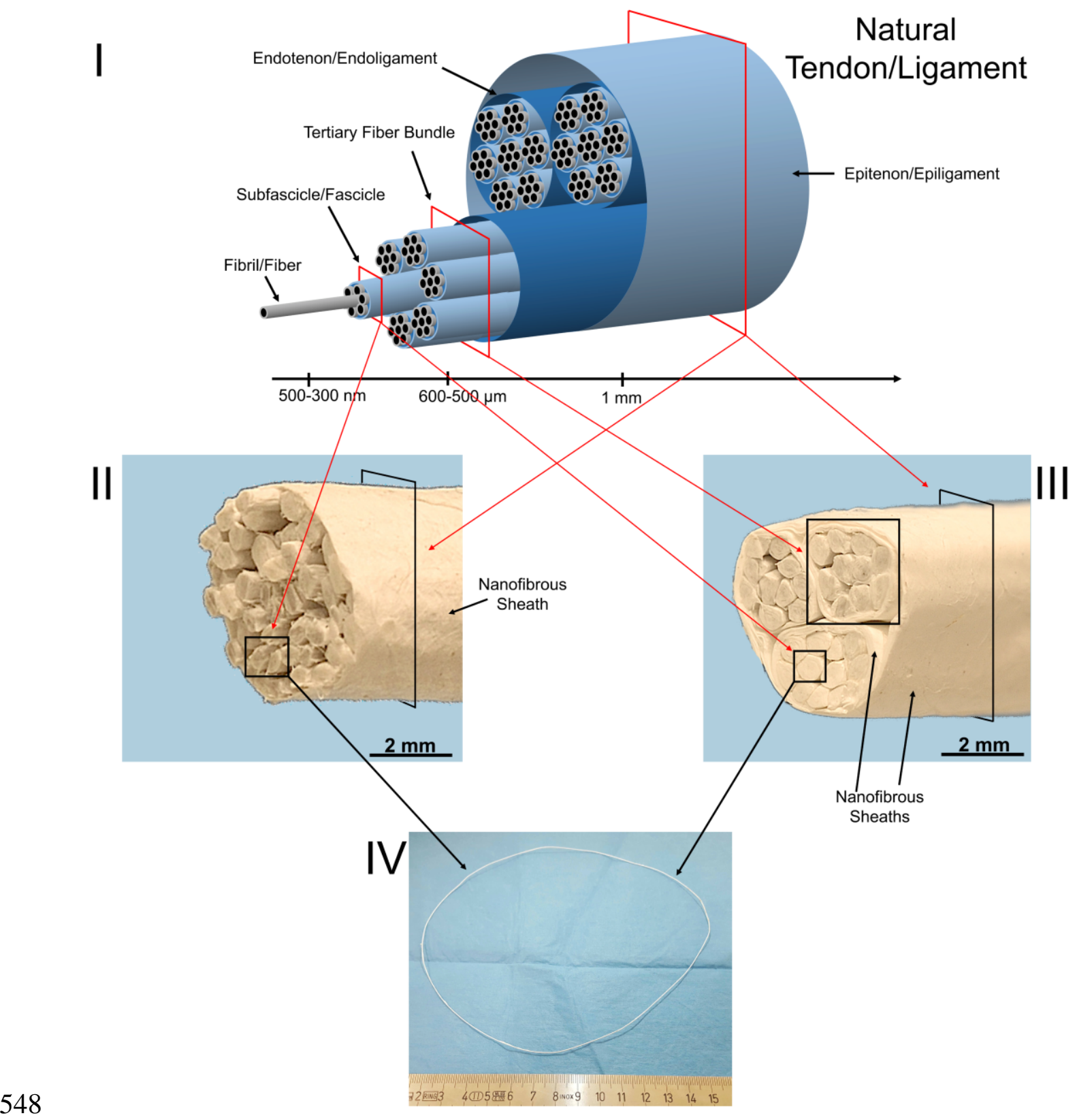

549 Fig. 6 - Comparison between a natural tendon or ligament and the electrospun 550 hierarchical assemblies. I) Hierarchical structure of a tendon or ligament [4]. II) Image 551 of the cross-section of a 2nd-level hierarchical assembly. III) Image of the cross-section 552 of a 3rd-level hierarchical assembly. IV) Image of a ring-shaped bundle used to build 553 the hierarchical assemblies. 


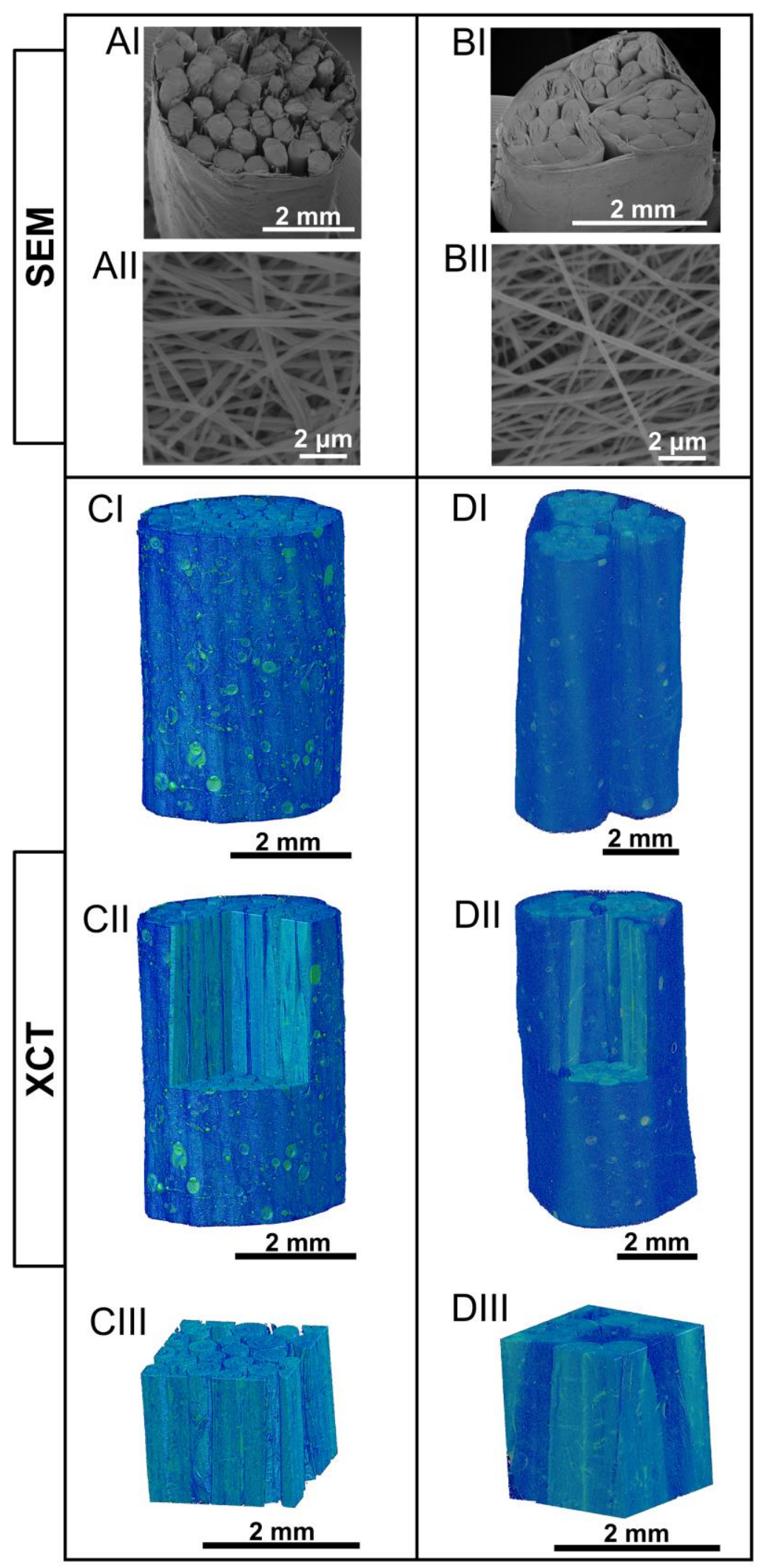

555 Fig. 7 - Imaging of the of the 2nd-level and 3rd-level hierarchical assemblies. A) SEM

556 images of a 2nd-level hierarchical assembly. B) SEM images of a 3rd-level hierarchical 
557 assembly. The sections of the hierarchical assemblies (magnification $=25 \mathrm{x}$ ) are visible 558 in part I; the nanofibers on the surface of the electrospun sheaths (magnification $=$

559 8000x) are visible in part II. C) XCT images of a 2nd-level hierarchical assembly (5.27

560 micrometers voxel size). D) XCT images of a 3rd-level hierarchical assembly (5.27

561 micrometers voxel size). An external section showing the external electrospun sheath

562 is visible in part I; an external crop showing the internal axially aligned bundles is

563 reported in part II; an internal crop showing the most internal axially aligned bundles

564 are visible in part III.
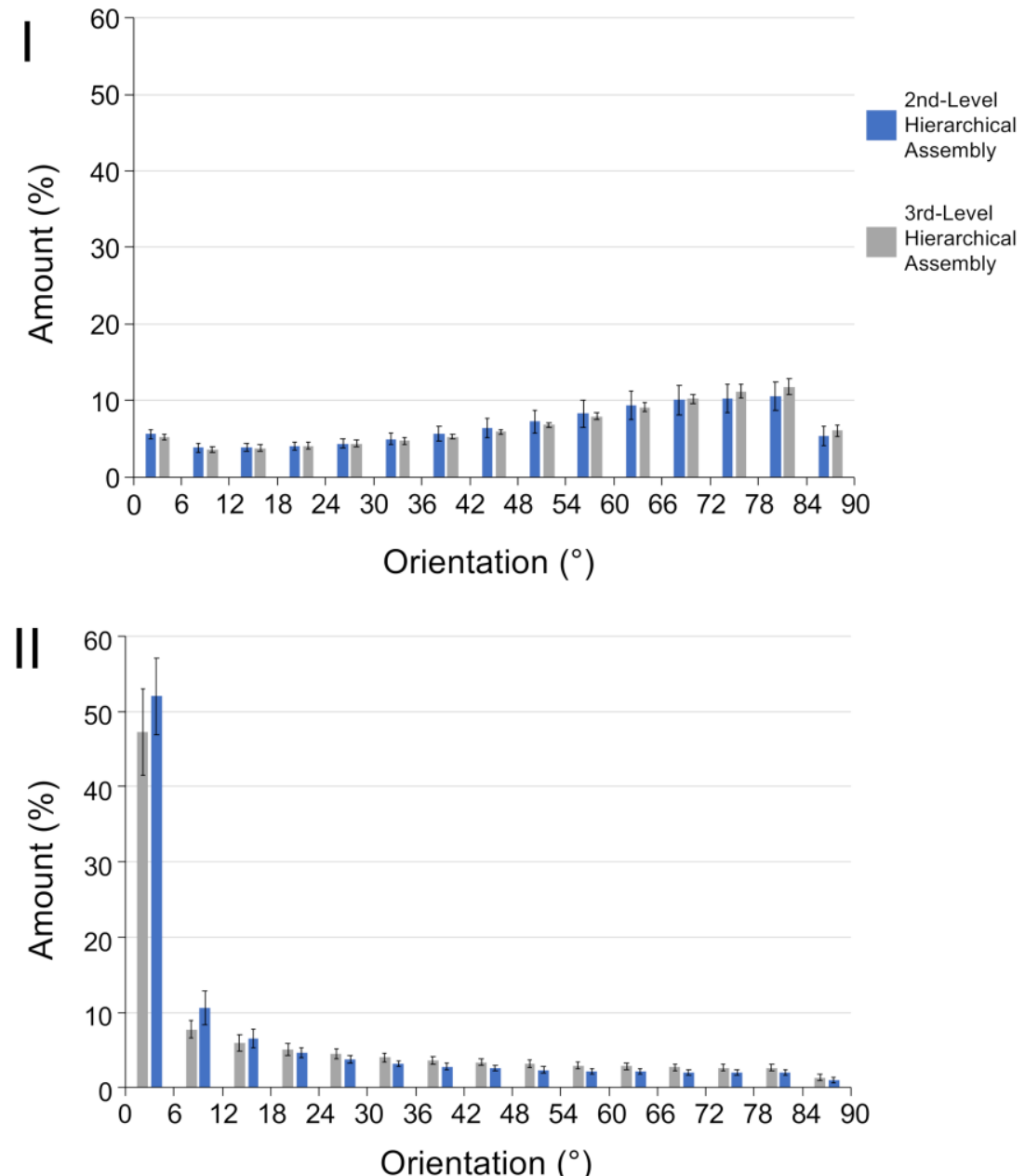

Orientation $\left({ }^{\circ}\right)$

566 Fig. 8 - Comparison between the alignment of the nanofibers in the outer sheaths (I) and 567 inside the assemblies (II) for the 2nd-level and the 3rd-level hierarchical assemblies. An 
568 angle of $0^{\circ}$ means that the nanofibers were aligned with the axis of the bundle, $90^{\circ}$ means

569 that the nanofibers were perpendicular to the bundle.
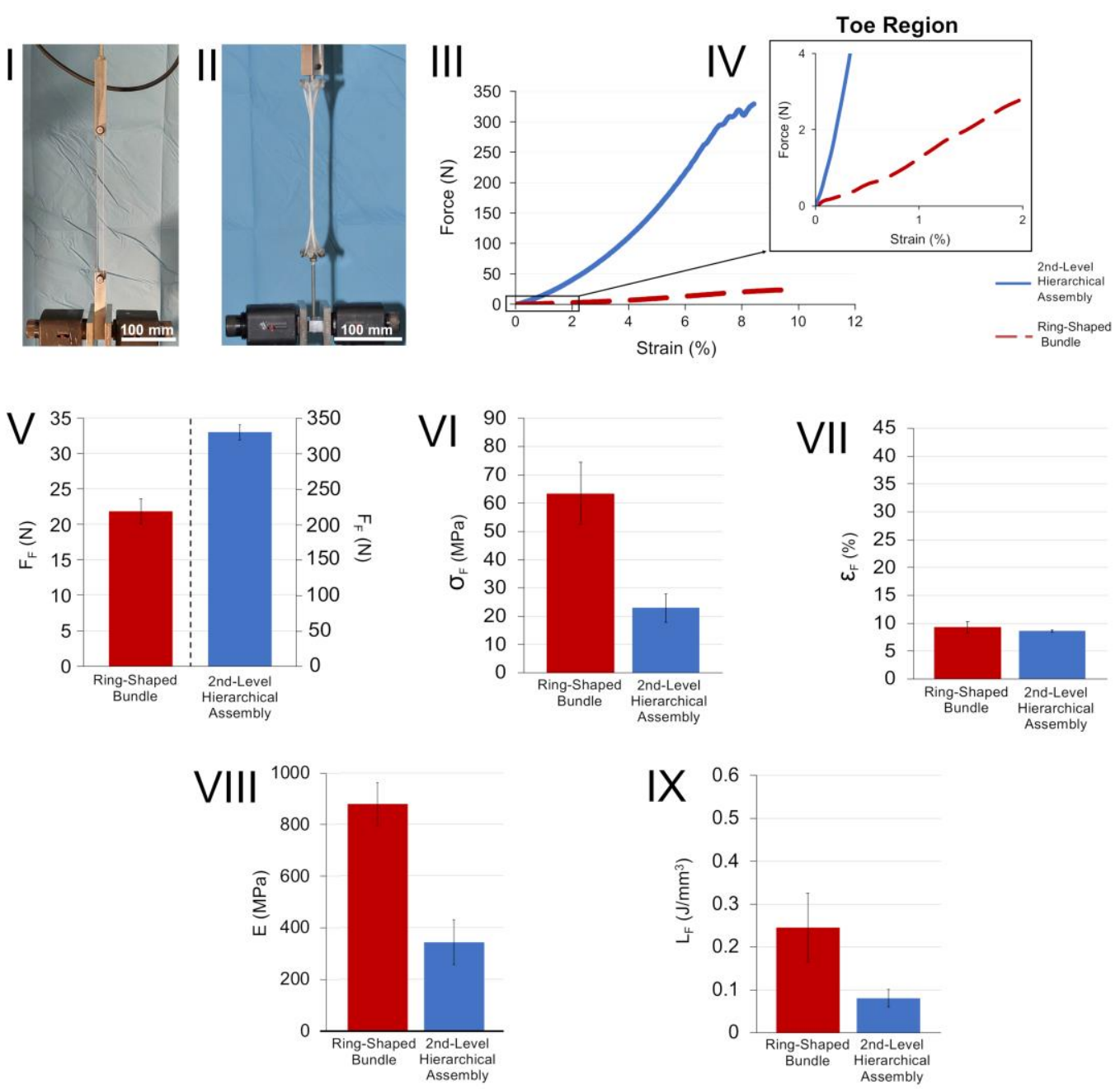

571 Fig. 9 - Mechanical characterization of the ring-shaped bundles and of the 2nd-level

572 hierarchical assembly. I) tensile testing of the ring-shaped bundles using custom-made

573 capstan grips; II) tensile testing of the 2nd-level hierarchical assembly using the 6-arms

574 capstan grips. III) typical load-strain curves of the ring aligned nanofiber bundles and

575 of the 2nd-level hierarchical assemblies; IV) zoom-in the nonlinear toe regions.

576 Comparison between the mechanical properties of the bundles and the 2nd-level

577 hierarchical assemblies: V) failure force $\left.\left(\mathrm{F}_{\mathrm{F}}\right) ; \mathrm{VI}\right)$ apparent failure stress $\left(\sigma_{\mathrm{F}}\right)$; VII) 
578 failure strain $\left(\varepsilon_{\mathrm{F}}\right)$; VIII) apparent modulus of elasticity (E); IX) apparent unit work to

579 failure $\left(\mathrm{L}_{F}\right)$. The corresponding net mechanical properties are reported in Table 1.

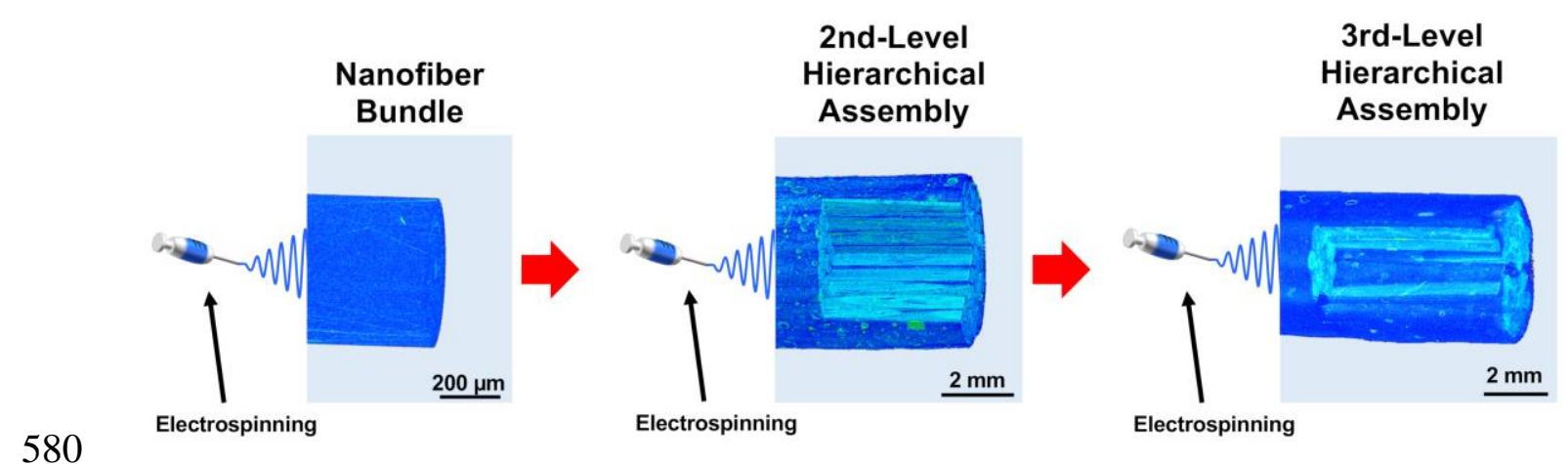

581 Graphical Abstract

582 


\section{Tables}

Table 1. Net mechanical properties of the bundles and the 2nd-level hierarchical assemblies obtained from the apparent ones, considering the fraction of volume $(v)$ actually taken by the nanofibers.

\begin{tabular}{|c|c|c|c|c|}
\hline & $\begin{array}{l}\text { Yield } \\
\text { stress } \\
(\mathrm{MPa})\end{array}$ & $\begin{array}{l}\text { Failure } \\
\text { stress } \\
\text { (MPa) }\end{array}$ & $\begin{array}{l}\text { Modulus of } \\
\text { Elasticity } \\
\text { (MPa) }\end{array}$ & $\begin{array}{l}\text { Unit work } \\
\text { to failure } \\
\left(\mathrm{J} / \mathrm{mm}^{3}\right)\end{array}$ \\
\hline $\begin{array}{l}\text { Random } \\
\text { Bundle }\end{array}$ & $15.6 \pm 3.12$ & $75.5 \pm 13.1$ & - & - \\
\hline $\begin{array}{l}\text { Aligned } \\
\text { Bundle }\end{array}$ & - & $235 \pm 28.6$ & - & - \\
\hline $\begin{array}{l}\text { Ring-shaped } \\
\text { Bundle }\end{array}$ & - & $389 \pm 65.3^{*}$ & $5390 \pm 421.1$ & $1.56 \pm 0.484$ \\
\hline $\begin{array}{l}\text { 2nd-level } \\
\text { Hierarchical } \\
\text { Assembly }\end{array}$ & - & $106 \pm 4.04^{*}$ & $1589 \pm 41.20$ & $0.372 \pm 0.0200$ \\
\hline
\end{tabular}

Note*: a slightly lower failure stress was found for the aligned bundles compared to the ring-shaped ones, in relation to the different gripping system (the gripping system used in the first case induced a higher stress concentration than with the ring-shaped bundles) 


\section{References}

[1] Abbah SA, Spanoudes K, O'Brien T, Pandit A, Zeugolis D. Assessment of stem cell carriers for tendon tissue engineering in pre-clinical models. Stem Cell Res Ther 2014;5:1-9. doi:10.1186/scrt426.

[2] Zeugolis DI, Chan JCY, Pandit A. Tendons: Engineering of Functional Tissues. In: Pallua N, Suscheck C, editors. Tissue Eng. From Lab to Clin. Tissue Eng, Springer Berlin Heidelberg; 2011, p. 1-634. doi:10.1007/978-3-642-02824-3.

[3] Kastelic J, Galeski A, Baer E. The Multicomposite Structure of Tendon. Connect Tissue Res 1978;6:11-23. doi:10.3109/03008207809152283.

[4] Kannus P. Structure of the tendon connective tissue. Scand J Med Sci Sport 2000;10:312-20. doi:10.1034/j.1600-0838.2000.010006312.x.

[5] Goh KL, Listrat A, Béchet D. Hierarchical mechanics of connective tissues: Integrating insights from nano to macroscopic studies. J Biomed Nanotechnol 2014;10:2464-507. doi:10.1166/jbn.2014.1960.

[6] McCarthy MM, Hannafin JA. The Mature Athlete: Aging Tendon and Ligament. Sports Health 2014;6:41-8. doi:10.1177/1941738113485691.

[7] Woo SLY, Hollis JM, Adams DJ, Lyon RM, Takai S. Tensile properties of the human femur-anterior cruciate ligament-tibia complex: The effects of specimen age and orientation. Am J Sports Med 1991;19:217-25. doi:10.1177/036354659101900303.

[8] Chen J, Xu J, Wang A, Zheng M. Scaffolds for tendon and ligament repair: review of the efficacy of commercial products. Expert Rev Med Devices 2014;6:61-73. doi:10.1586/17434440.6.1.61.

[9] Maitz MF. Applications of synthetic polymers in clinical medicine. Biosurface and Biotribology 2015;1:161-76. doi:10.1016/j.bsbt.2015.08.002.

[10] Capperauld I. Suture materials: A review. Clin Mater 1989;4:3-12. doi:10.1016/0267-6605(89)90021-8.

[11] Boileau P, Brassart N, Watkinson DJ, Carles M, Hatzidakis AM, Krishnan SG. Arthroscopic repair of full-thickness tears of the supraspinatus: Does the tendon really heal? J Bone Jt Surg - Ser A 2005;87:1229-40. doi:10.2106/JBJS.D.02035.

[12] Longo UG, Lamberti A, Maffulli N, Denaro V. Tendon augmentation grafts: A systematic review. Br Med Bull 2010;94:165-88. doi:10.1093/bmb/ldp051.

[13] Jackson DW, Heinrich JT, Simon TM. Biologic and synthetic implants to replace the anterior cruciate ligament. Arthrosc J Arthrosc Relat Surg 1994;10:442-52. doi:10.1016/S0749-8063(05)80197-5.

[14] Murphy W, Black J, Hastings G. Handbook of Biomaterial Properties. Second. Springer; 2016. doi:10.1007/978-1-4939-3305-1.

[15] Batty LM, Norsworthy CJ, Lash NJ, Wasiak J, Richmond AK, Feller JA. Synthetic devices for reconstructive surgery of the cruciate ligaments: A 
systematic review. Arthrosc - J Arthrosc Relat Surg 2015;31:957-68. doi:10.1016/j.arthro.2014.11.032.

[16] Brunet P, Charrois O, Degeorges R, Boisrenoult P, Beaufils P. Reconstruction of acute posterior cruciate ligament tears using a synthetic ligament. Rev Chir Orthop Reparatrice Appar Mot 2005;91:34-43. doi:MDOI-RCO-02-2005-91-10035-1040-101019-200510479 [pii].

[17] Engstrom B, Wredmark T, Westblad P. Patellar tendon or Leeds-Keio graft in the surgical treatment of anterior cruciate ligament ruptures. Intermediate results. Clin Orthop Relat Res 1993:190-7.

[18] Ochi M, Yamanaka T, Sumen Y, Ikuta Y. Arthroscopic and histologic evaluation of anterior cruciate ligaments reconstructed with the Leeds-Keio ligament. Arthrosc J Arthrosc Relat Surg 1993;9:387-93. doi:10.1016/S07498063(05)80312-3.

[19] Rading J, Peterson L. Clinical Experience with the Leeds-Keio Artificial Ligament in Anterior Cruciate Ligament Reconstruction: A Prospective TwoYear Follow-up Study. Am J Sports Med 1995;23:316-9. doi:10.1177/036354659502300311.

[20] Murray AW, Macnicol MF. 10-16 year results of Leeds-Keio anterior cruciate ligament reconstruction. Knee 2004;11:9-14. doi:doi:10.1016/S09680160Ž03.00076-0.

[21] Hirooka A, Yoneda M, Wakaitani S, Isaka Y, Hayashida K, Fukushima S, et al. Augmentation with a Gore-Tex patch for repair of large rotator cuff tears that cannot be sutured. J Orthop Sci 2002;7:451-6. doi:10.1007/s007760200078.

[22] Kollender Y, Bender B, Weinbroum AA, Nirkin A, Meller I, Bickels J. Secondary reconstruction of the extensor mechanism using part of the quadriceps tendon, patellar retinaculum, and gore-tex strips after proximal tibial resection. J Arthroplasty 2004;19:354-60. doi:10.1016/j.arth.2003.11.004.

[23] Muren O, Dahlstedt L, Brosjö E, Dahlborn M, Dalén N. Gross osteolytic tibia tunnel widening with the use of Gore-Tex anterior cruciate ligament prosthesis: A radiological, arthrometric and clinical evaluation of 17 patients 13-15 years after surgery. Acta Orthop 2005;76:270-4. doi:10.1080/00016470510030689.

[24] Miller MD, Peters CL, Allen B. Early Aseptic Loosening of a Total Knee Arthroplasty Due to Gore-Tex Particle-Induced Osteolysis. J Arthroplasty 2006;21:765-70. doi:10.1016/j.arth.2005.07.021.

[25] O'Connor RA, McGuinness GB. Electrospun nanofibre bundles and yarns for tissue engineering applications: A review. Proc Inst Mech Eng Part H J Eng Med 2016;230:987-98. doi:10.1177/0954411916656664.

[26] Brennan DA, Conte AA, Kanski G, Turkula S, Hu X, Kleiner MT, et al. Mechanical Considerations for Electrospun Nanofibers in Tendon and Ligament Repair. Adv Healthc Mater 2018;1701277:1-31. doi:10.1002/adhm.201701277.

[27] Sensini A, Cristofolini L. Biofabrication of Electrospun Scaffolds for the Regeneration of Tendons and Ligaments. Materials (Basel) 2018;11:1963. 
doi:10.3390/ma11101963.

[28] Liu Z. Scale space approach to directional analysis of images. Appl Opt 1991;30:1369-73. doi:https://doi.org/10.1364/AO.30.001369.

[29] Schindelin J, Arganda-Carreras I, Frise E, Kaynig V, Longair M, Pietzsch T, et al. Fiji: an open-source platform for biological-image analysis. Nat Methods 2012;9:676-82. doi:10.1038/nmeth.2019.

[30] Schneider CA, Rasband WS, Eliceiri KW. NIH Image to ImageJ: 25 years of image analysis. Nat Methods 2012;9:671-5. doi:10.1038/nmeth.2089.

[31] Sensini A, Cristofolini L, Focarete ML, Belcari J, Zucchelli A, Kao A, et al. Highresolution X-ray tomographic morphological characterisation of electrospun nanofibrous bundles for tendon and ligament regeneration and replacement. $\mathbf{J}$ Microsc 2018;272:196-206. doi:10.1111/jmi.12720.

[32] Butler DL. Anterior cruciate ligament: its normal response and replacement. J Orthop Res 1989;7:910-21. doi:10.1002/jor.1100070618.

[33] Lewis G, Shaw KM. Tensile properties of human tendo Achillis: effect of donor age and strain rate. J Foot Ankle Surg 1997;36:435-45. doi:10.1016/S10672516(97)80096-8.

[34] Wren TA., Yerby SA, Beaupré GS, Carter DR. Mechanical properties of the human achilles tendon. Clin Biomech 2001;16:245-51. doi:10.1016/S02680033(00)00089-9.

[35] Lee M, Hyman W. Modeling of failure mode in knee ligaments depending on the strain rate. BMC Musculoskelet Disord 2002;3:1-8. doi:https://doi.org/10.1186/1471-2474-3-3.

[36] Moshiri A, Oryan A. Tendon and Ligament Tissue Engineering, Healing and Regenerative Medicine. J Sports Med Doping Stud 2013;3:1-18. doi:10.4172/2161-0673.1000126.

[37] Hanson P, Aagaard P, Magnusson SP. Biomechanical properties of isolated fascicles of the Iliopsoas and Achilles tendons in African American and Caucasian men. Ann Anat 2012;194:457-60. doi:10.1016/j.aanat.2012.03.007.

[38] Kannus P, Paavola M, Józsa L. Aging and degeneration of tendons. In: Maffulli N, Renström P, W.B. L, editors. Tendon Inj., London: Springer; 2005, p. 25-31. doi:10.1007/1-84628-050-8_4.

[39] Provenzano PP, Vanderby R. Collagen fibril morphology and organization: Implications for force transmission in ligament and tendon. Matrix Biol 2006;25:71-84. doi:10.1016/j.matbio.2005.09.005.

[40] Sensini A, Gualandi C, Cristofolini L, Tozzi G, Dicarlo M, Teti G, et al. Biofabrication of bundles of poly(lactic acid)-collagen blends mimicking the fascicles of the human Achille tendon. Biofabrication 2017;9. doi:10.1088/17585090/aa6204.

[41] Sensini A, Gualandi C, Zucchelli A, Boyle L, Kao AP, Reilly GC, et al. Tendon Fascicle-Inspired Nanofibrous Scaffold of Polylactic acid/Collagen with 
Enhanced 3D-Structure and Biomechanical Properties. Sci Rep 2018;8:1-15. doi:https://doi.org/10.1038/s41598-018-35536-8.

[42] Zhou FL, Gong R-H, Porat I. Nano-coated hybrid yarns using electrospinning. Surf Coatings Technol 2010;204:3459-63. doi:10.1016/j.surfcoat.2010.04.021.

[43] Kohlman LW, Roberts GD. Method for coating tow with an electrospun nanofiber. US8932683B1, 2015. doi:10.1016/j.(73).

[44] Naghashzargar E, Farè S, Catto V, Bertoldi S, Semnani D, Karbasi S, et al. Nano/micro hybrid scaffold of PCL or P3HB nanofibers combined with silk fibroin for tendon and ligament tissue engineering. J Appl Biomater Funct Mater 2015;13:e156-68. doi:10.5301/jabfm.5000216.

[45] Li D, Pan X, Sun B, Wu T, Chen W, Huang C, et al. Nerve conduits constructed by electrospun P(LLA-CL) nanofibers and PLLA nanofiber yarns. J Mater Chem B 2015;3:8823-31. doi:10.1039/C5TB01402F.

[46] Banik BL, Lewis GS, Brown JL. Multiscale Poly-(€-caprolactone) Scaffold Mimicking Non-linearity in Tendon Tissue Mechanics. Regen Eng Transl Med 2016;2:1-9. doi:10.1007/s40883-016-0008-5.

[47] Butler DL, Kay MD, Stouffer DC. Fascicle-Bone Units From Human Patellar Tendon and Knee Ligaments. J Biomech 1986;19:425-32. doi:https://doi.org/10.1016/0021-9290(86)90019-9.

[48] Xu Y, Dong S, Zhou Q, Mo X, Song L, Hou T, et al. The effect of mechanical stimulation on the maturation of TDSCs-poly(L-lactide-co-ecaprolactone)/collagen scaffold constructs for tendon tissue engineering. Biomaterials 2014;35:2760-72. doi:10.1016/j.biomaterials.2013.12.042.

[49] Bosworth LA. Travelling along the Clinical Roadmap: Developing Electrospun Scaffolds for Tendon Repair. Conf Pap Sci 2014;2014:1-6. doi:10.1155/2014/304974.

[50] Mouthuy P-A, Zargar N, Hakimi O, Lostis E, Carr A. Fabrication of continuous electrospun filaments with potential for use as medical fibres. Biofabrication 2015;7:25006. doi:10.1088/1758-5090/7/2/025006.

[51] Laranjeira M, Domingues RMA, Costa-Almeida R, Reis RL, Gomes ME. 3D Mimicry of Native-Tissue-Fiber Architecture Guides Tendon-Derived Cells and Adipose Stem Cells into Artificial Tendon Constructs. Small 2017;13:1-13. doi:10.1002/smll.201700689.

[52] Abhari RE, Mouthuy PA, Vernet A, Schneider JE, Brown CP, Carr AJ. Using an industrial braiding machine to upscale the production and modulate the design of electrospun medical yarns. Polym Test 2018;69:188-98. doi:10.1016/j.polymertesting.2018.05.014.

[53] Tare M. Dental rolls: A suitable model for practising tendon repair techniques. J Hand Surg Am 2004;29:506-7. doi:10.1016/j.jhsb.2004.05.006.

[54] Ingraham JM, Weber RA, Weber RA. Utilizing a simulated tendon to teach tendon repair technique. Hand 2009;4:150-5. doi:10.1007/s11552-009-9184-9. 
[55] Abdulal S, Onyekwelu O. An alternative model for teaching tendon repair and surgical skills in plastic surgery. JPRAS Open 2016;7:12-5. doi:10.1016/j.jpra.2015.11.003.

[56] Bosworth LA, Rathbone SR, Bradley RS, Cartmell SH. Dynamic loading of electrospun yarns guides mesenchymal stem cells towards a tendon lineage. $\mathbf{J}$ Mech Behav Biomed Mater 2014;39:175-83. doi:10.1016/j.jmbbm.2014.07.009.

[57] Bradley RS, Robinson IK, Yusuf M. 3D X-Ray Nanotomography of Cells Grown on Electrospun Scaffolds. Macromol Biosci 2017;17:1-8. doi:10.1002/mabi.201600236. 